\title{
Drought dynamics in the East European Plain for the period 1980-2018
}

\author{
Maxim Kharlamov ${ }^{1,2^{*}}$, Maria Kireeva $^{1}$ \\ ${ }^{1}$ Lomonosov Moscow State University, 1 Leninskie Gory, 119991, Moscow, Russia \\ ${ }^{2}$ Water Problems Institute of the RAS, 3 Gubkina st., 119333, Moscow, Russia
}

\begin{abstract}
Drought is one of the most dangerous natural hazards that has a huge impact on the economy and population in the world and in Russia as well. A large number of studies speak of an increase in the number of droughts and low flow conditions, including Russia. In this work, an analysis was made of the conditions for droughts in the East European Plain over the past 38 years based on the data from the ERA- 5 reanalysis. The atmospheric precipitation, air temperature over the seasons and the Palmer index (as a general indicator) for the study area were analyzed. Much attention was paid to the characteristics of the winter period, since the supposedly mild winters create favorable conditions for the formation of droughts in the summer period. It was found that the main factors affecting the drought formation of 2007-2018 was the lack of summer rainfall, and the remaining factors played a "preparatory" role in the process of the formation of large-scale drought.
\end{abstract}

\section{Introduction}

Drought is one of the most dangerous natural hazards in terms of damage to the economy [1]. In 2015, a drought swept the vast territory of Central and Southern Europe and resulted in significant economic losses amounting to millions of euros [1]. Drought is largely determined not only by natural conditions, but also by the connectedness of economic sectors with them. The more developed the region is, the greater the number of sectors of the economy depends on hydroclimatic conditions [2].

In world practice, a large number of the drought indices are used to assess these phenomena, which reflect the conditions for the formation of dry periods in vast territories [3]. Basically, these indices are interconnected, but each has a number of features, and is used for certain conditions [4]. The most common indices are SPI and SPEI [3].

The Palmer Drought Severity Index, proposed in 1965, is widely used in many countries of the world. This indicator is calculated on the basis of meteorological data (air temperature and precipitation), as well as local constants characterizing soil moisture capacity [5]. The selection of indices reflecting the conditions of aridity should correspond to the developed classification of droughts, which is widely used in world practice [6]. In

\footnotetext{
*Corresponding author: kharlamov.m.a@gmail.com
} 
accordance with this or other similar classifications, strategies for responding and preventing the effects of droughts on a global and national scale are being developed [7]. In Russia at the moment there is no open system for collecting and storing information on dry conditions for the entire observation period. The drought monitoring center [8] and the Roshydromet hazardous events monitoring center [9] are operating on-line; information on the impact of dry conditions is also partially published on the website of the Water Resources Agency [10].

\section{Materials and methods}

The study was conducted for the European territory of Russia. As baseline data to describe the climatic changes of recent years, daily data of air temperature and precipitation reanalysis ERA5 [11] for the period 1980-2018, with a spatial resolution of 0.25x0.25.

For each point in the grid node, the following meteorological characteristics were calculated: the number of days with negative air temperature, the duration of the winter period, the average temperature of the air for the winter and summer period, the amount of solid precipitation for the winter period, the amount of liquid precipitation for the winter period, the amount of liquid precipitation for the summer period.

In this case, during the winter period, the period of time from the first transition of air temperature through $0^{\circ} \mathrm{C}$ to the moment of the last transition of the air temperature through $0 \mathrm{C}$. The resulting series of characteristics were averaged for two periods (1980 - 2006 and 2007-2018), and then their difference was analyzed.

To determine the localization of droughts, their severity and duration, the well-known self-calibrated Palmer Drought Index (scPDSI) [12], also calculated on the basis of ERA5 reanalysis data for the period 1980 - 2018 with help of climate_indices, an open source Python library [13].

The Palmer Index uses average monthly air temperature and monthly precipitation, as well as a constant that characterizes soil moisture. The calculation of the index is based on a simplified scheme of water balance on the surface of the soil. This index considers the cumulative effect, so the values of the index at the moment of time depend on the previous interval, which is a big advantage over the SPI and SPEI indices. Negative index values show the degree of dryness: from 0 to -1 - normal hydration, from -1 to $-2-$ a weak drought, from -2 to -3 - moderate drought, from -3 to $-4-$ extreme drought.

\section{Results}

Over the past 10 years in study region there has been a significant change in the temperature regime of the winter period. Winters have become much warmer, as can be seen from Fig.1 a. Almost the entire East European Plain (EEP) area has an increase in average winter air temperature (except for the eastern part, where there is a slight decrease in the average of 0.3 degrees). Against the background of the increase in the average winter temperature there is a decrease in the number of days with negative temperature (Fig. $1 \mathrm{~b}$ ). 

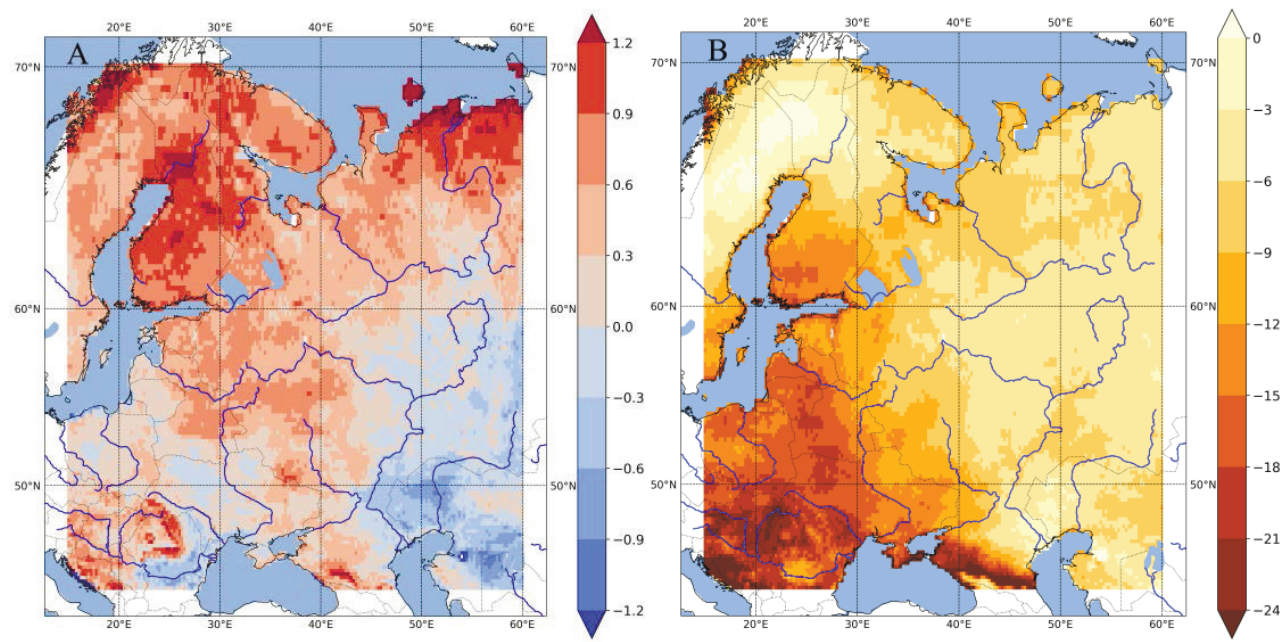

Fig. 1. Changes in winter air temperature (in Celsius) averaged for 2007-2018 in compared to average for 1980-2006 (a) and changes in number of days with negative temperature during winter (b) average for 2007-2018 in compared to average for 1980-2006 (in \%).

The increase in winter air temperature, in turn, affects both the total amount of snow that has fallen, and the stability of the snow cover (Fig. 2a). The amount of solid precipitation decreased by an average of 10-15 per cent throughout the territory. Against the background of rising winter temperatures, solid precipitation for the central part of the EEP was partially offset by liquid precipitation (Fig 2.b). On contrast there is a strong reduction in liquid winter precipitation for the Northern Dvina River Basin and Lower Volga River Basin (up to $20 \%$ ).
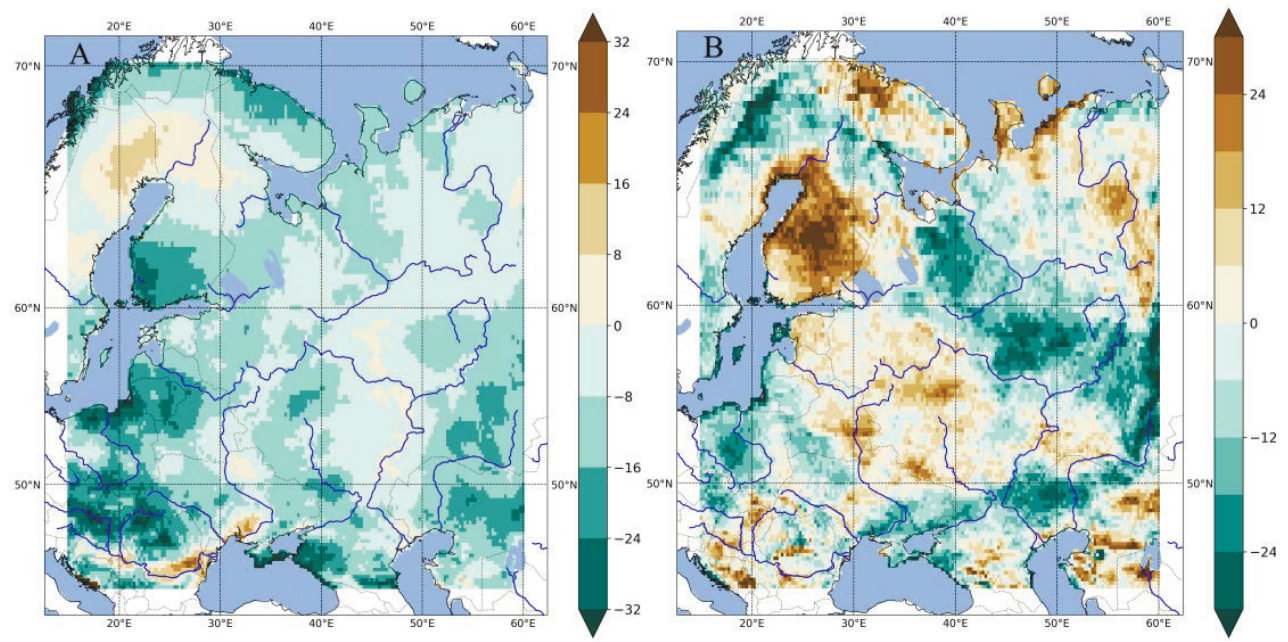

Fig. 2. Changes in solid (a) and liquid (b) precipitation in \% during winter period on East European Plain (average for 2007-2018 in compared to average for 1980-2006).

The summer period is characterized by a significant decrease in precipitation in the central and southern part of the EEP (Fig. 3.a). The Basins of the Lower and Middle Volga, as well as the Don basin, were most affected. Precipitation in this area decreased by $20 \%$. For the northern part of the EEP, precipitation increases by $10-15 \%$. For the summer period, as well as for winter, there is a significant increase in air temperature for southern 
EEP (Fig. 3.b). The Basins of the Lower and Middle part of Volga River, as well as the Don River Basin, were the hardest hit. The average summer temperature increased by 0.75

$-1^{\circ} \mathrm{C}$. In the northern part of the EEP, the growth is not so significant, only $0.25-0.5^{\circ} \mathrm{C}$.

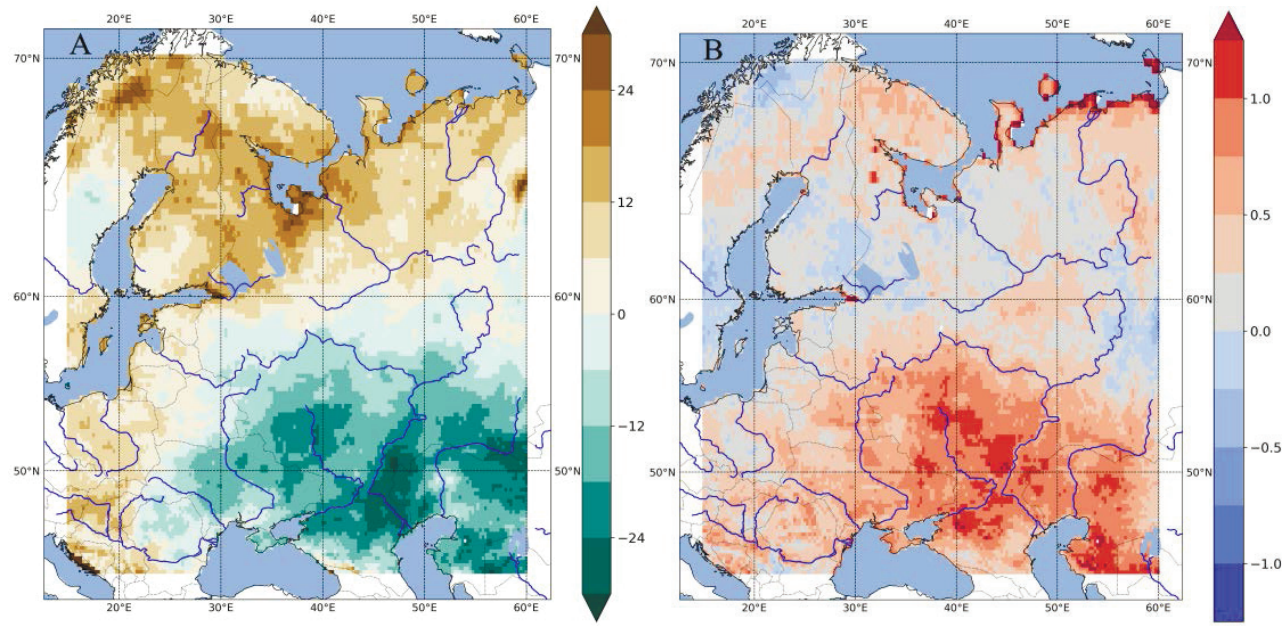

Fig. 3. Changes in liquid precipitation (in \%) during summer (a) and average temperature (in Celsius) during summer (b) averaged for 2007-2018 in compared to average for 1980-2006.

The scPDSI drought index shows that the central and southern part of study area has experienced a persistent dry season over the past 10 years except for the northwest (Fig 4.b). The core of the drought is located in the basin of the middle part of Volga River Basin, as well as in the Don River Basin. Average values of the scPDSI index for the Middle Volga River Basin and the Don River Basin are -4.2 , which corresponds to extreme drought.

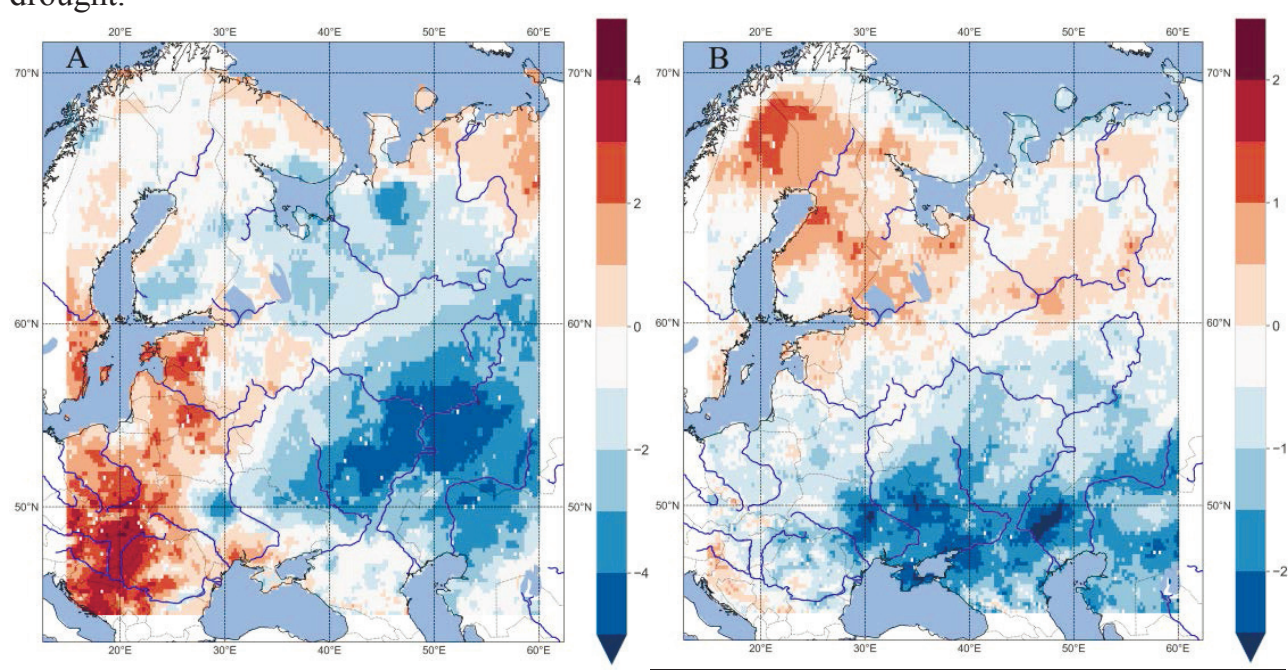

Fig. 4. Average value of scPDSI for 2010 (a) and for 2007-2018 (b).

\section{Conclusions}

Based on the analysis of changes in temperature and precipitation in the East-European Plain, it can be concluded that the greatest role in the occurrence of the dry period of 2007 - 
2018 was the reduction of precipitation in the summer period, taking place against the background of the increase in the average temperature of the summer period, and therefore the increase in evaporation.

The general "drying" of the soil of the central and southern parts of the region leads to an increase in losses during the snow-forming period, which against the background of a decrease in the amount of solid precipitation is one of the main causes in the degradation of main seasonal snowmelt flood for the rivers of the Don and Volga basins. The absence of spring flood leads to important consequences in terms of the formation of droughts.

The small volumes of meltwater that enter the reservoirs do not allow the full restoration of perennial volumes for regulation. As a result, water systems are in short supply. This, in turn, leads to a worsening of the effects of droughts in the long-term period.

The study was carried out with the financial support of the grant of RSF No. 19-77-10032.

\section{References}

1. H.A.J Van Lanen, G. Laaha, E. Rets, N. Frolova, M. Kireeva, et al., Hydrol. Process. 30, 3097-3104 (2016)

2. $\quad$ A.F Van Loon, T. Gleeson, J. Clark, et al. Nature Geoscience 9, 89-91 (2016)

3. N. Wanders, A.F. Van Loon, H.A.J. Van Lanen. Hydrol. Earth Syst. Sci. Discuss. (to be published)

4. J.H. Stagge, L.M. Tallaksen, L. Gudmundsson, A.F. Van Loon, K. Stahl, Int. J. of Climate.13, 4027-4040 (2015)

5. W.M. Alley, J. of Appl. Meteo. 23, 1100-1109 (1984)

6. A.F. Van Loon, H.A.J. Van Lanen, Hydrol. and Earth Sys. Sci.16, 1915-1946 (2012)

7. D.A. Wilhite. National Drought Management Policy Guidelines: A Template for Action, IDMP, Report, 48 pp. WMO: Geneva, Switzerland and GWP (2014)

8. Drought Monitoring Center of the All-Russian Research Institute of Agricultural Meteorology. Available online: http://cxm.obninsk.ru/index.php?id=200 (accessed on 20 December 2019)

9. The system of monitoring hazardous events of Roshydromet. Available online: https://meteoinfo.ru/ (accessed on 20 December 2019)

10. The official website of the Agency for Water Resources of the Russian Federation. Available online: http://voda.mnr.gov.ru/ (accessed on 20 December 2019)

11. H. Hersbach, D. Dee, ERA5 reanalysis is in production. ECMWF Newsletters. April 2016. Number 147. Available online: https://www.ecmwf.int/en/newsletter/147/news/ era5-reanalysis -production (accessed on 20 December 2019)

12. N. Wells, S. Goddard and M.J. Hayes, J. of Climate, 17: 2335-2351 (2004)

13. J. Adams. climate_indices, an open source Python library providing reference implementations of commonly used climate indices. May 2017. Available online: https://github.com/monocongo/climate indices (accessed on 20 December 2019) 